\title{
Super Dye Adsorption Capability of Natural Superfine Down Particles for Organic Contaminant from Binary Dye Mixture ${ }^{\star}$
}

\author{
Fengxiang Chen ${ }^{\mathrm{a}, \mathrm{b}}$, Huiyu Yang ${ }^{\mathrm{a}}$, Yaling Wang ${ }^{\mathrm{b}}$, Keshuai Liu ${ }^{\mathrm{a}}$, \\ Xin Liu ${ }^{\mathrm{a}, *}, \quad$ Weilin $\mathrm{Xu}^{\mathrm{a}, *}$ \\ ${ }^{a}$ State Key Laboratory of New Textile Materials and Advanced Processing Technologies, Wuhan Textile \\ University, Wuhan 430200, China \\ ${ }^{\mathrm{b}}$ Beijing Advanced Innovation Center for Biomedical Engineering and Key Laboratory of Bio-inspired \\ Smart Interfacial Science and Technology of Ministry of Education, School of Chemistry, Beihang \\ University, Beijing 100191, China
}

\begin{abstract}
Reuse of waste resources is still a challenging issue for public health and ecosystem protection. Herein, natural superfine down particles (NSDP) were successfully prepared from the wasted down fibers and investigated for the removal of methylene blue (MB) and methyl orange (MO) dyes from the binary dye solution. The adsorbent was characterized by scanning electron microscopy (SEM) and $\mathrm{N}_{2}$ adsorption. The adsorption behavior of NSDP for these two dyes was investigated as a function of $\mathrm{pH}$. The results showed that the NSDP surface has surface area of $7277 \mathrm{~cm}^{2} / \mathrm{g}$ and an abundance of functional groups (carboxyl, hydroxyl and amine-groups). The adsorption capacity of NSDP was strongly pH-dependence. The results indicated that NSDP can be used as an efficient and economic adsorbent to remove dyes in the textile effluents.
\end{abstract}

Keywords: Natural Superfine Down Particle; Textile Wastewater; Dye Adsorption; pH

\section{Introduction}

As an important chemical products, organic dyes are widely used in various fields, including paper, leather, printing, food, cosmetics, paint, pigment, and so on [1]. However, their highly toxic nature have led to a series of environmental pollution problem. Discharge of wastewater containing organic dyes into the aquatic ecosystem without proper treatment poses a severe threat

\footnotetext{
${ }^{\star}$ Project supported by the National Natural Science Foundation of China (51773158, 51903008), 111 Project (Grant No. B14009), China Postdoctoral Science Foundation (Grant No. 2018M640042) and Open Foundation of State Key Laboratory of New Textile Materials \& Advanced Processing Technologies from Wuhan Textile University (WHFZDX-005) for financial support

*Corresponding author.

Email addresses: liuxin0111184@163.com (Xin Liu), weilin-xu@hotmail.com (Weilin Xu).
} 
to the environment, because these dyes affect the nature of the water, inhibit sunlight penetration into the stream and hinder photosynthetic reactions. In addition, some of these dyes are highly cytotoxic, mutagenic and carcinogenic to humans [2].

So far, the textile industry is the major contributor to aquatic pollution, and hence, the elimination of dyes from textile effluents is crucial. Attributed to these harmful impacts, much attention have been paid to remove the synthetic dyes from the printing and dyeing wastewater [3]. Various methods, including chemical oxidation [4-5], ion exchange [6], coagulation/flocculation [7-8], electrochemical treatment [9], photochemical treatment [10-11], biodegradation [12-13], and physical adsorption [14-17] have been explored for the decoloration of dyeing wastewater. Among these reported abatement methods, adsorption is considered useful for treating of industrial effluents because of its simplicity, efficiency, low operation cost and selectivity [18]. Therefore, it is vital to design an exceptional adsorbent include high selectivity and adsorption capacity, fast kinetics and good recycling properties

Down fibre, which are natural protein fibres, have long been used as high quality textile materials by virtue of their moderate moisture absorption and retention ability [19]. Poultry farms in China produce about 0.2 billion $\mathrm{kg}$ of down fibres every year. Much of the used fibre is processed into a low-quality protein supplement for animal feed, which leads to a huge waste of energy resources [20]. The possibility of using hen feathers as a potential adsorbent to remove organic dyes from textile effluents has been demonstrated [21-25], but the low adsorption capacity of this materials limits its commercial application.

Herein, we prepared natural superfine down particles (NSDP), which had a 14-fold larger Brunauer-Emmett-Teller surface area $\left(\mathrm{S}_{\mathrm{BET}}\right)$ and the greater number of surface hydrophilic (hydroxyl, carboxyl, and amino) groups, compared to goose down fibres. The main aim of our study was to explore the possibility of utilizing the prepared NSDP for the removal of organic dyes from aqueous solutions. Methylene blue $\left(\mathrm{MB}, \lambda_{\max }=660 \mathrm{~nm}\right)$ and methyl orange $\left(\mathrm{MO}, \lambda_{\max }=465\right.$ $\mathrm{nm}$ ) were chosen as the adsorbates. These two dyes are commonly used in textile/dyeing industries and are often discharged into water bodies without purification/treatment.

\section{Materials and Methods}

\section{$2.1 \quad$ Materials}

Down fibers of ducks were collected from a local poultry farm in Wuhan, China. The dyes, including MB and MO were purchased from Tianjing Jiedi Co. Ltd. (Tianjing, China), used without further purification.

\subsection{Preparation and Characterization of NSDP}

The details of our laboratory-scale NSDP preparation process have been described in an earlier publication $[19,26]$. Briefly, the collected down fibres were washed thoroughly with deionized water for 3-4 times for removal of mixed dirt and any other granular impurities. Then, the cleaned down fibres were dried in an oven at $105^{\circ} \mathrm{C}$ for $3 \mathrm{~h}$. The dried fibres were cut into short pieces with a specialized rotary blade and soaked for $24 \mathrm{~h}$ in a mixed solution with the $20 \%(\mathrm{v} / \mathrm{v}$ ) aqueous ethanol and $30 \%(\mathrm{v} / \mathrm{v})$ hydrogen peroxide at room temperature. The soaked fibres were 
further washed with deionized water, dried at $105^{\circ} \mathrm{C}$ for $3 \mathrm{~h}$ and shattered by a purely physical method using our in-house machine. The equipment was previously reported in the US patent of US 7000858B2 and Chinese patent of ZL 02154128.0.

The surface morphologies of the NSDP were observed by scanning electron microscopy (SEM, JSM7600F, JEOL Ltd., Japan) at an electron acceleration voltage of $25 \mathrm{kV}$. Prior to scanning, the sample was sputter-coated with a thin layer of gold to make it conductive. The $\mathrm{S}_{\mathrm{BET}}$ value of the NSDP was determined by $\mathrm{N}_{2}$ adsorption/desorption at $-196{ }^{\circ} \mathrm{C}$ using a Micromeritics ASAP 2020 analyser (Mike Corporation, USA).

\subsection{Adsorption Experiments}

Batch adsorption experiment with binary dye (MB and MO dye) were carried out at room temperature $\left(25^{\circ} \mathrm{C}\right)$. In the binary dyes solutions, $25 \mathrm{ml}$ of $\mathrm{MB}$ and same amount of $\mathrm{MO}$ dye solutions with fixed concentrations were mixed in a $100 \mathrm{ml}$ flask. Thereafter $0.1 \mathrm{~g}$ of NSDP was added to the flask containing $50 \mathrm{~mL}$ of total dye solution and a pre-adjusted $\mathrm{pH}$. The $\mathrm{pH}$ of the solutions was adjusted with $0.1 \mathrm{~mol} / \mathrm{L} \mathrm{HCl}$ or $\mathrm{NaOH}$. The flasks were agitated at a constant speed of 200 rpm for $4 \mathrm{~h}$ on an SHZ-82 isothermal water-bath shaker. The supernatant liquid was centrifuged at $12000 \mathrm{rpm}$ for $10 \mathrm{~min}$, and the residual dye concentrations in each flask was determined by $\mathrm{UV} / \mathrm{Vis}$ spectrophotometry (SHIMADZU, UV-2550). Residual MB and MO dye concentrations in the binary dye solutions were calculated by using Equation 1 and 2 with components of MB and $\mathrm{MO}$, which were measured at $\lambda_{\mathrm{MBmax}}$ and $\lambda_{\mathrm{MOmax}}$ respectively to give absorbance of $\mathrm{A}_{\mathrm{MB}}$ and $\mathrm{A}_{\mathrm{MO}}$.

$$
\begin{aligned}
C_{\mathrm{MB}} & =\frac{k_{\mathrm{MOMO}} A_{\mathrm{MB}}-k_{\mathrm{MOMB}} A_{\mathrm{MO}}}{k_{\mathrm{MBMB}} k_{\mathrm{MOMO}}-k_{\mathrm{MBMO}} k_{\mathrm{MOMB}}} \\
C_{\mathrm{MO}} & =\frac{k_{\mathrm{MBMB}} A_{\mathrm{MO}}-k_{\mathrm{MBMO}} A_{\mathrm{MB}}}{k_{\mathrm{MBMB}} k_{\mathrm{MOMO}}-k_{\mathrm{MBMO}} k_{\mathrm{MOMB}}}
\end{aligned}
$$

where $k_{\mathrm{MBMB}}, k_{\mathrm{MOMB}}, k_{\mathrm{MBMO}}$, and $k_{\mathrm{MOMO}}$ refer to the calibration constants for components MB and MO at two wavelengths $\lambda_{\mathrm{MBmax}}$ and $\lambda_{\mathrm{MOmax}}$, respectively. $C_{\mathrm{MB}}$, and $C_{\mathrm{MO}}$ represents the concentrations of MB dye and MO dye after adsorption.

\section{Results and Discussion}

The optical images of down fibers and NSDP and SEM micrographs of NSDP are presented in Fig. 1(a-c). The NSDP exhibited a white colour, similar to the natural down fibre, suggesting that the native properties of fibre were well preserved during the preparation process. The surface of the NSDP was very rough with many pores, which provided a large exposed surface area for dye adsorption. The average diameters of the NSDP were determined to be $2-4 \mu \mathrm{m}$. The $\mathrm{N}_{2}$ adsorption/desorption experiments revealed that the surface area of the NSDP was $7277 \mathrm{~cm}^{2} / \mathrm{g}$, which was beneficial for dye absorption.

Since down fibers are a structural protein fibers, the presence of amine groups on the surface of the NSDP means that the $\mathrm{pH}$ in the aqueous solution have an important effect on the dye adsorption. The impact not only the surface charge of the adsorbent, the degree of ionization of the material present in the solution and the dissociation of functional groups on the active sites 

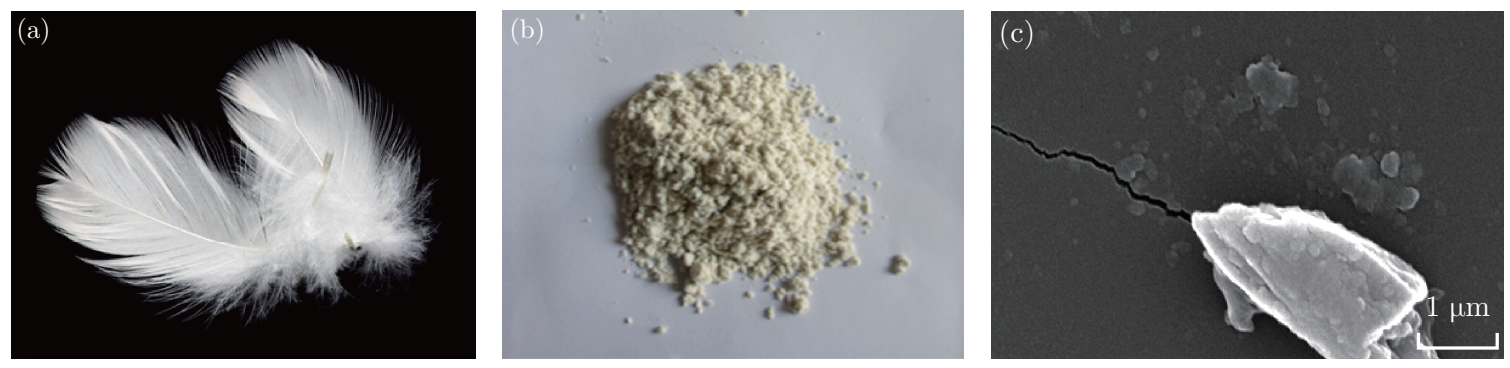

Fig. 1: Surface morphology. (a) Optical images of down fibers, (b) optical images of NSDP and (c) SEM micrographs of NSDP

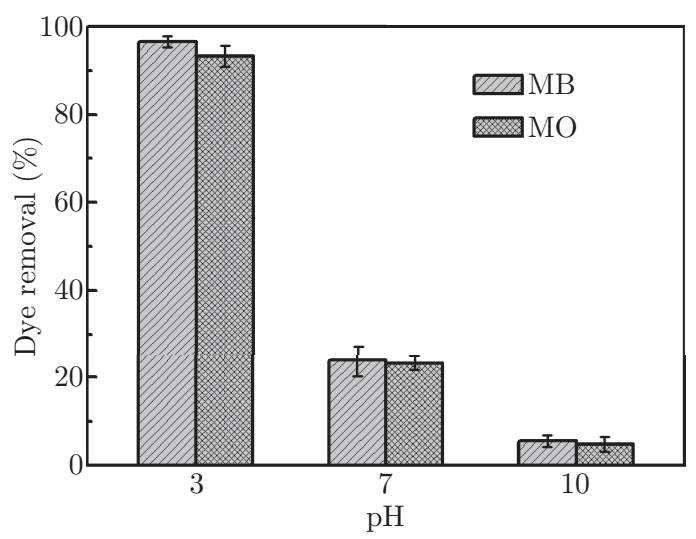

Fig. 2: $\mathrm{pH}$ dependence of $\mathrm{MB}$ and $\mathrm{MO}$ dyes removal onto NSDP

of the adsorbent, but also the solution dye chemistry. To elucidate the adsorption mechanism, the adsorption was first carried out with $0.1 \mathrm{~g}$ of NSDP dispersed in $50 \mathrm{~mL}$ of dye solution but at varied $\mathrm{pH}$ levels (Fig. 2). Clearly, the adsorption of $\mathrm{MB}$ was strongly $\mathrm{pH}$-dependence. The dye removal percentage of the NSDP declined sharply as the $\mathrm{pH}$ was increased from 3 to 7 and then further decreased when the $\mathrm{pH}$ was increased to 10 , but the trend was less pronounced than

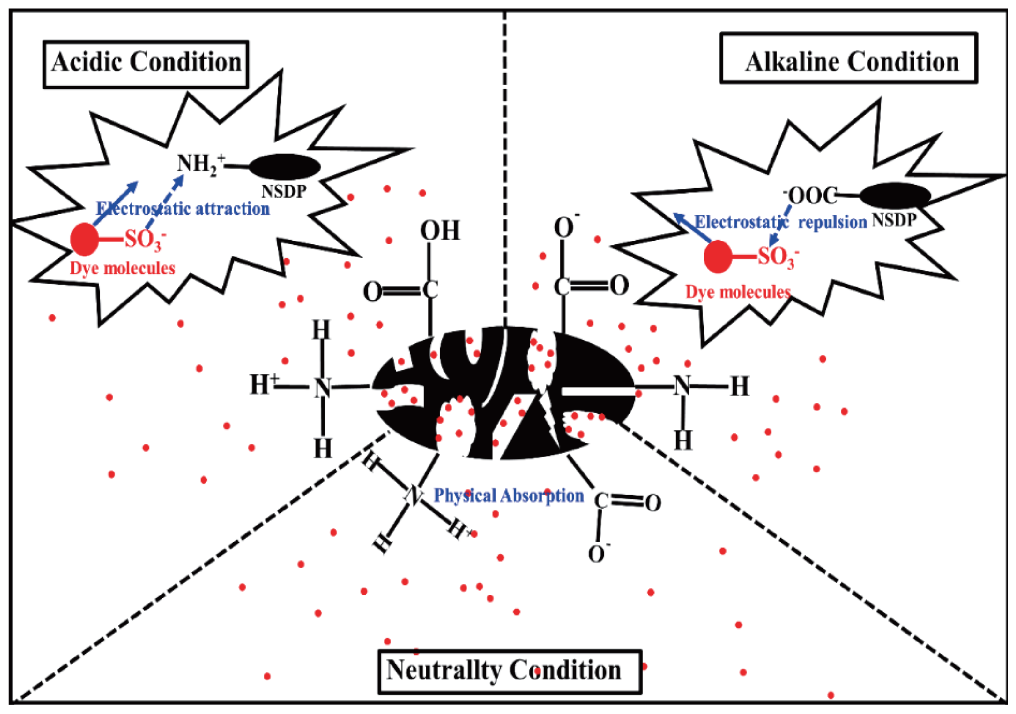

Scheme 1: Surface charge of NSDP at various solution environmental and the adsorption mechanisms 
the acidic condition. Interestingly, the adsorption behavior for the MO also exhibited a similar trend. The maximum dye removal percentage onto the NSDP was observed at pH 3.

This trend can be explained by the change in the surface charge of the NSDP (Scheme 1). The higher adsorption of the dyes at lower $\mathrm{pH}$ may be due to an increase in the number of protonated groups, such as carboxylic, phenolic and amino groups by neutralization of the negative charge and the electrostatic attraction on the surface of the NSDP, which is helpful for the dyes adsorption by electrostatic interaction. As the $\mathrm{pH}$ increases beyond $\mathrm{pH}_{\mathrm{pzc}}$, the number of positively charged sites on the adsorbents decreases due to the weakened protonation, and the electrostatic repulsive force becomes operative between the adsorbent surface and the dyes, thereby retarding dye diffusion and adsorption. In addition, the abundance of $\mathrm{OH}^{-}$ions competing with the negatively charged dye molecules for the adsorption sites is responsible for the lower adsorption of the dyes at high $\mathrm{pH}$. Besides electrostatic attraction, the partial degradation of NSDP is also responsible for the poor dye adsorption capacity at elevated $\mathrm{pH}$ levels.

\section{Conclusions}

In this study, we successfully prepared NSDP and utilized them for the adsorption of two common industrial dyes, MB and MO, from the binary dye mixture solutions. The results of SEM and $\mathrm{N}_{2}$ adsorption experiments revealed the rough surface with many pores, the average diameters of the NSDP were 2-4 $\mu \mathrm{m}$ and the surface area was $7277 \mathrm{~cm}^{2} / \mathrm{g}$. The adsorption behaviour of the NSDP for the MB and MO was investigated as a function of $\mathrm{pH}$. The optimum conditions for adsorption were determined, the most efficient adsorption was achieved at $\mathrm{pH} 3$. In all, these findings indicate that NSDP would be an ideal adsorbent for dyes from industrial wastewaters.

\section{Acknowledgement}

We greatly acknowledge the financial support from the National Natural Science Foundation of China (51773158, 51903008), 111 Project (Grant No. B14009), China Postdoctoral Science Foundation (Grant No. 2018M640042) and Open Foundation of State Key Laboratory of New Textile Materials \& Advanced Processing Technologies from Wuhan Textile University (WHFZDX-005).

\section{References}

[1] Wang S, Boyjoo Y, Choueib A. Removal of dyes from aqueous solution using fly ash and red mud. Water. Res. 2005; 39: 129-138.

[2] Uzum OB, Karadag E, Uptake of basic blue 17 from aqueous solutions by using chemically crosslinked polyelectrolyte AAm/AASS hydrogels. Adsorption. 2006; 12: 77-88.

[3] Chowdhury S, Chakraborty S, Saha P. Biosorption of basic green 4 from aqueous solution by ananas comosus (pineapple) leaf powder. Colloid. Surf. B. 2011; 84: 520-527.

[4] Körbahti BK. Response surface optimization of electrochemical treatment of textile dye wastewater. J. Hazard. Mater. 2009; 145: 277-286. 
[5] Gokkus O, Ciner F. Investigation of color and cod removal from wastewater containing disperse yellow 119 and disperse red 167 using fenton oxidation process. J. Fac. Eng. Arch. Gazi. Univ. 2010; 25: 49-55.

[6] Sari M, Akgöl S, Karatas M, Denizli A. Reversible immobilization of catalase by metal chelate affinity interaction on magnetic beads. Ind. Eng. Chem. Res. 2006; 45: 3036-3034.

[7] Meriç S, Selçuk H, Belgiorno V. Acute toxicity removal in textile finishing wastewater by Fenton's oxidation, ozone and coagulation-flocculation processes. Water. Res. 2005; 39: 1147-1153.

[8] Phalakornkule C, Polgumhang S, Tongdaung W, Karakat B, Nuyut T. Electrocoagulation of blue reactive, red disperse and mixed dyes, and application in treating textile effluent. J. Environ. Manage. 2010; 91: 918-926.

[9] Shen ZM, Wu D, Yang J, Yuan T, Wang WH, Jia JP. Methods to improve electrochemical treatment effect of dye wastewater. J. Hazard. Mater. 2006; 131: 90-97.

[10] Guettai N, Amar HA. Photocatalytic oxidation of methyl orange in presence of titanium dioxide in aqueous suspension. Part I: parametric study. Desalination. 2005; 185: 427-437.

[11] Zainal Z, Lee CY, Hussein MZ, Kassim A, Yusuf NA. Electrochemical-assisted photodegradation of dye on $\mathrm{TiO}_{2}$ thin films: investigation on the effect of operational parameters. J. Hazard. Mater. 2005; 118: 197-203.

[12] Chang JS, Chou C, Lin YC, Lin PJ, Ho JY, Hu TL. Kinetic characteristics of bacterial azo-dye decolorization by Pseudomonas luteola. Water. Res. 2001; 35: 2841-2850.

[13] Tan NCG, Prenafeta-Boldu FX, Opsteeg JL, Lettinga G, Field JA. Biodegradation of azo dyes in cocultures of anaerobic granular sludge with aerobic aromatic amine degrading enrichment cultures. Appl. Microbiol. Biotechnol. 1999; 51: 865-871.

[14] Mittal A, Kaur D, Malviya A, Mittal J, Gupta V. Adsorption studies on the removal of coloring agent phenol red from wastewater using waste materials as adsorbents. J. Colloid. Interface. Sci. 2009; 337: 345-354.

[15] Gupta V, Suhas. Application of low-cost adsorbents for dye removal - A review. J. Environ. Manage. 2009; 90: 2313-2342.

[16] Ravikumar K, Ramalingam S, Krishnan S, Balu K. Application of response surface methodology to optimize the process variables for reactive red and acid brown dye removal using a novel adsorbent. Dyes. Pigments. 2006; 70: 18-26.

[17] Nigam P, Armour G, Banat IM, Singh D, Marchant R. Physical removal of textile dyes from effluents and solid-state fermentation of dye-adsorbed agricultural residues. Bioresource. Technol. 2000, 72: 219-226.

[18] Xiong L, Chen FX, Yan XM, Mei P. The adsorption of dibenzothiophene using activated carbon loaded with cerium. J. Porous. Mater. 2012; 19: 713-719.

[19] Xu WL, Cui WG, Li W, Guo WQ. Development and characterizations of super-fine wool powder. Powder. Technol. 2004; 140: 136-140.

[20] Liu X, Xu WL, Li WB, Chen YB, Rao J. Mechanical and water vapor transport properties of polyurethane/superfine down powder composite membranes. Polym. Eng. Sci. 2010; 12: 24002407.

[21] Mittal A, Thakur V, Gajbe V. Evaluation of adsorption characteristics of an anionic azo dye brilliant yellow onto hen feathers in aqueous solutions. J. Environ. Sci. Pollut. Res. 2012; 19: 2438-2447.

[22] Mittal A, Thakur V, Gajbe V. Adsorptive removal of toxic azo dye amido black 10B by hen feather. J. Environ. Sci. Pollut. Res. 2013; 20: 260-269.

[23] Mittal A. Use of hen feathers as potential adsorbent for the removal of a hazardous dye brilliant blue FCF, from wastewater. J. Hazard. Mater. 2006; B128: 233-239. 
[24] Mittal A. Adsorption kinetics of removal of a toxic dye, malachite green, from wastewater by using hen feathers. J. Hazard. Mater. 2006; B133: 196-202.

[25] Gupta VK, Mittal A, Kurup L, Mittal J. Adsorption of a hazardous dye, erythrosine, over hen feathers. J. Colloid. Interf. Sci. 2006; 304: 52-57.

[26] Tao YZ, Yan Y, Xu WL, Physical characteristics and properties of waterborne polyurethane materials reinforced with silk fibroin powder. J. Polym. Sci. Pt. B.-Polym. Phys. 2010; 48: 940-945. 